\title{
CONTRIBUIÇÕES DA TEORIA DA ICONICIDADE VERBAL PARA O ENSINO DE LÍNGUA E LITERATURA
}

Márcia da Gama Silva Felipe (UERJ/SEEDUC/SME)

Resumo: No atual contexto de globalização, aprender uma língua vai além da simples tradução do código verbal, engloba também a compreensão de fatores culturais e identitários. O presente artigo tem por objetivo propor estratégias de leitura e interpretação de texto, tendo como corpus de análise o romance Vidas Secas, de Graciliano Ramos. Propomos o uso do texto literário como corpus propício ao ensino de Língua Portuguesa, de forma a oferecer ao aluno o aprendizado do código verbal, enriquecido pela compreensão dos respectivos aspectos culturais. Buscamos embasamento teórico-prático na Teoria da Iconicidade Verbal, cuja metodologia permite a reconstituição da trilha lexical, identificada na superfície do texto, com fins de identificação de usos e costumes. Acreditamos que o texto literário, como representante da cultura de um povo, contribui significativamente para o ensino da língua, e para a eficácia na leitura e interpretação de textos.

Palavras-chave: Teoria da Iconicidade Verbal. Língua. Literatura. Identidade. Ensino.

Abstract: In the current globalization context learning a language goes beyond the simple verbal code translation, it also encompasses the understanding of identity and cultural factors. This article intends to offer reading strategies and text interpretation, based on the analysis of the corpus of Vidas Secas, a novel by Graciliano Ramos. We suggest the use of the literary text as an appropriate corpus to the Portuguese Language teaching, in order to offer the students the verbal code learning, improved by the respective understanding of cultural aspects. We seek theoretical-practical basis in the Theory of Verbal Iconicity, whose methodology allows the reconstruction of the lexical path, identified on the surface of the text, for the purpose of identifying uses and customs. We believe that the literary text, as a representative of the culture of a people, contributes significantly for language teaching, and for the effectiveness in reading and interpreting texts.

Key-words: Theory of Verbal Iconicity. Language. Literature. Identity. Teaching. 


\section{PALAVRAS INICIAIS}

"Preste muita atenção no texto que vais folhear Tem a influência de Darcilia Simões, impossivel não falar Competência é seu nome, por codinome é Dadá Desde 2015, esteve a me orientar. Rígida em seus preceitos, Tenaz em seus argumentos, Mas quem a conhece de perto, Sabe que é puro sentimento. A homenagem é singela, Quisera fosse magistral, Mas como homenagear a mãe Da Teoria da Iconicidade Verbal?" Márcia Felipe

Se há uma palavra para identificar a professora Darcilia Simões é o adjetivo curiosa. É essa curiosidade que faz dela uma pesquisadora determinada, criteriosa e pertinaz em suas investigações, que desbrava a densa floresta das palavras com o fito de identificar-lhes o caminho percorrido pela seiva que subjaz ao significado. Curiosa pela própria natureza, dentre tantos caminhos possíveis, Simões escolhe o da Semiótica para o estudo do significado. Por que um texto significa o que significa? Essa é uma das questões que aguçam sua curiosidade e a partir da qual, a estudiosa persegue a trilha deixada pelo autor na construção do texto.

Suas pesquisas constituem um marco da Semiótica na Universidade do Estado do Rio de Janeiro. Instituição 
onde, ladeada por seus pares na luta por uma educação superior de qualidade, trouxe ao Instituto de Letras a ciência inaugurada por Charles Sanders Peirce. Não há como falar de Darcilia Simões sem mencionar sua vasta produção acadêmica e, mais diretamente, a Teoria da Iconicidade Verbal por ela desenvolvida. A aplicação dessa teoria na análise do texto verbal é o que será demonstrado nos próximos parágrafos.

\section{TRADIÇÃO E MODERNIDADE}

No atual mundo globalizado, as fronteiras geográficas não configuram barreiras para a interação nem para o compartilhamento de práticas e culturas diversas; vive-se a era da velocidade na comunicação e da interculturalidade. Mediante esse cenário, o indivíduo é desafiado a apreender uma série de falares e práticas que, muitas vezes, vão de encontro a suas concepções, crenças ou vivências. A reboque dessas manifestações culturais, constatam-se movimentos sociais que impõem uma tomada de posição e, não raramente, provocam desestabilização na identidade do indivíduo ou mesmo de um grupo social. Esses fatos não são exclusivos da contemporaneidade, mas estão intrinsecamente ligados às relações sociais e interpessoais; por isso, tratar de temas concernentes à identidade é sempre necessário. 
Ainda que, hodiernamente, haja uma grande incidência e valorização do texto midiático, multimodal e de rápido consumo, o texto literário continua atual no tratamento de inúmeras questões da formação humana. Por isso, considera-se que o ensino da Língua Portuguesa, tendo como córpus de análise o texto literário, possibilita a abordagem de três grandes temas inerentes à formação de todo ser humano: língua, cultura e identidade. A necessária combinação desses três temas no ensino de línguas é a razão pela qual são desenvolvidas as investigações aqui propostas.

A despeito disso, sabe-se que o cânone da literatura nacional pouco tem figurado nas pesquisas voltadas às questões da Língua Portuguesa, especialmente com o enfoque ora proposto. No âmbito do ensino, observa-se, com bastante frequência, o uso de fragmentos de textos com fins estritamente gramaticais. A leitura integral de um romance, por exemplo, encontra dificuldade nos bancos escolares devido a uma série de fatores, dentre eles: a não existência de um número razoável de volumes de um mesmo título para leitura pelos discentes; a dificuldade na compreensão do vocabulário; o tempo dedicado à leitura, normalmente inexistente, em sala de aula e a falta de motivação. 
Perante essa realidade, torna-se necessário que o ensino de língua e literatura alcancem uma abordagem diferenciada, cujo objetivo seja o de enriquecer o aprendizado da leitura, da interpretação e da produção textual. Nessa mesma vertente, encontram-se os documentos oficiais que incentivam a formação do leitor crítico, preconizando uma abordagem linguístico-semiótica, com o reconhecimento da função social da literatura na formação humana.

\section{A BNCC E O ENSINO DE LÍNGUA PORTUGUESA}

O valor da leitura é inegável. Desde os documentos oficiais à fala cotidiana é unânime o reconhecimento de sua importância na formação pessoal e profissional. O Ministério da Educação tem estabelecido diretrizes para o ensino da Língua Portuguesa em todo o território brasileiro e desenvolvido algumas ações com o intuito de unificar as bases desse ensino. Para tanto, foram desenvolvidos, inicialmente, os Parâmetros Curriculares Nacionais (PCN) e a Lei de Diretrizes e Bases (LDB), documentos cujos conteúdos são complementares nessa implementação.

É importante destacar que, ainda na introdução aos PCN, destaca-se a necessidade de adequação do ensino de Língua Portuguesa à diversidade regional e cultural do país. O texto afirma que: 
O Brasil é um país com grande diversidade regional, cultural e com grandes desigualdades sociais; portanto, não é possível pensar em um modelo único para incorporação de recursos tecnológicos na educação. É necessário pensar em propostas que atendam aos interesses e necessidades de cada região ou comunidade. (BRASIL, 1998, p. 140)

A preocupação do documento com as dimensões geográficas e a diversidade linguística do Brasil são, por si só, suficientes para respaldar a ideia de uma educação plural, de modo a atender as especificidades de cada região. Com uma visão bastante semelhante aos PCN, o governo federal instituiu a Base Nacional Comum Curricular (BNCC), que retoma os parâmetros iniciais, porém, de forma ampliada, abrangendo as novas configurações sociais e tecnológicas. Citando o PCN, a BNCC determina sua postura que seria a de assumir uma

perspectiva enunciativo-discursiva de linguagem, já assumida em outros documentos, como os Parâmetros Curriculares Nacionais (PCN), para os quais a linguagem é "uma forma de ação interindividual orientada para uma finalidade específica; um processo de interlocução que se realiza nas práticas sociais existentes numa sociedade, nos distintos momentos de sua história" (BRASIL, 2017, p. 67) 
Com essa visão, a BNCC vem, principalmente, trazer um tom de atualização e de modernidade às estratégias educacionais, introduzindo novos gêneros e novas formas de letramento, carreados pelas modernas propostas tecnológicas. Contudo, a despeito do incentivo ao uso das novas tecnologias e ferramentas digitais, a proposta principal é a de possibilitar a formação do cidadão para sua atuação social e interpessoal com base no domínio da língua materna. Seja no âmbito do Ensino Fundamental ou do Ensino Médio, esse discurso é compartilhado pela BNCC. A competência específica no 4, para o Ensino Médio, da BNCC remete à compreensão das

línguas como fenômeno (geo)político, histórico, cultural, social, variável, heterogêneo e sensível aos contextos de uso, reconhecendo suas variedades e vivenciando-as como formas de expressões identitárias, pessoais e coletivas, bem como agindo no enfrentamento de preconceitos de qualquer natureza. (BRASIL, 2017, p. 494)

Destaca-se nesse trecho a preocupação que a base curricular revela em relação à expressão das identidades, individual e coletiva, e ao combate ao preconceito. O desenvolvimento dessa competência não ocorre por acaso, nem de forma imediata, mas com abordagem criteriosa de conteúdos e temáticas pertinentes desde o Ensino 
Fundamental. O desenvolvimento dessa habilidade deve ser inerente ao projeto pedagógico das escolas e aos objetivos didáticos dos professores, a fim de que

ao final do Ensino Médio, os estudantes compreenderem as línguas e seu funcionamento como fenômeno marcado pela heterogeneidade e variedade de registros, dialetos, idioletos, estilizações e usos, respeitando os fenômenos da variação e diversidade linguística, sem preconceitos. Ela também diz respeito à utilização das línguas de maneira adequada à situação de produção dos discursos, considerando a variedade e o registro, os campos de atuação social, e os contextos e interlocutores específicos, por meio de processos de estilização, seleção e organização dos recursos linguísticos. (BRASIL, 2017, p. 494)

A Lei de Diretrizes e Bases (LDB) ำ 9.394, de 20 de dezembro de 1996, publicada no Artigo 3ㅇ, estabelece alguns princípios que norteiam o ensino. Dentre eles, destaca-se o inciso XII, acrescentado pela Lei no 12.796, de 2013, que alerta quando à "consideração com a diversidade étnicoracial" no processo de ensino-aprendizagem.

Como se pode ver, existe uma preocupação legal com um ensino abrangente, cujo alcance atenda à diversidade característica da cultura brasileira e que combata o preconceito linguístico, a partir da valorização dos falares 
regionais, com suas especificidades. Insiste-se, pois, na necessidade do ensino contextualizado, no ensino dos fatos gramaticais condizente com uma análise crítica do ato de comunicação, garantindo ao alunado as ferramentas necessárias ao uso eficiente da língua.

Em outra vertente, o ensino de Literatura, normalmente colocado como uma disciplina à parte da Língua Portuguesa, precisa ir além das classificações dos textos nas respectivas escolas literárias ou da pesquisa em torno da biografia dos autores. Essa necessidade fundamenta-se no fato de que, com raras exceções, o alunado não apresenta cabedal léxico que o conduza de modo tranquilo na leitura do texto; principalmente, quando tem em mãos uma obra do cânone literário. Em função disso, a necessidade de repensar a prática da sala de aula torna-se exercício inerente ao ofício do professor.

Para o enfrentamento da realidade e dos objetivos aqui evidenciados, propõe-se o ensino da língua numa vertente linguístico-semiótica com base no texto literário. Essa abordagem vai ao encontro dos objetivos apresentados pelos planos de ensino, visto que contempla a cultura nacional, a representação da identidade e o conhecimento da diversidade linguística. 


\section{(RE)CONHECENDO O BRASIL}

A diversidade linguística inerente ao território nacional brasileiro associada à deficiência no ensino de língua e literatura produz um resultado preocupante no desenvolvimento de leitores críticos. Dessa forma, correse o risco de aumentar a lacuna já existente entre as variedades inerentes à Língua Portuguesa, tornando crônico um problema há muito denunciado por estudiosos e poetas. Vale lembrar um trecho de Querelas do Brasil de Adir Blanc e Maurício Tapajós, que bem representa esse quadro: "O Brazil não conhece o Brasil / O Brasil nunca foi ao Brazil". Na letra, que denuncia o abandono das raízes, o poeta seleciona palavras de origem indígena desconhecidas da maior parte dos brasileiros. Citando essa mesma obra, Simões (2004) destaca a importância da literatura como representativa do povo brasileiro, na simplicidade de roceiros, caipiras e lavradores; pessoas cuja sabedoria "cativa a todos que desse povo se aproximam, com olhos de descobrir o Brasil" (2017). A autora destaca ainda que:

O Brasil e suas dimensões continentais apresenta um mosaico étnico-cultural que se traduz nas práticas linguageiras de sua gente. Por isso, impõe-se uma revisão nos projetos político-educacionais, sobretudo na área das Letras, de modo a contemplar toda a gama de variedades linguísticas 
que atravessa nossa terra do Oiapoque ao Chuí, sem qualquer matiz discriminatório. (SIMÕES, 2004, p. 90)

Resta aos professores a função de resgatar a cultura regional, trazendo para a sala de aula conteúdo relevante que realmente contemple a diversidade linguística e cultural do Brasil, promovendo a afirmação da identidade com os diversos falares da Língua Portuguesa no território nacional. Evidencia-se, pois, a necessidade de tratamento do texto literário de forma a contribuir para um ensino profícuo da Língua Portuguesa, calcado na variação linguística e na abordagem cultural.

Em função disso, reitera-se a necessidade de que o ensino de leitura e escrita tenha uma abordagem contextualizada, visto que, as palavras ou expressões alcançam seu potencial sígnico no contexto de uso. A partir desse entendimento, os processos de ensino e aprendizagem de Língua Portuguesa, seja para o falante nativo ou não, devem ser concebidos de modo contextualizado, preferencialmente no uso formal, porque os demais usos são aprendidos na prática linguageira.

Entende-se ainda que a contribuição do texto literário para o ensino de língua alcança valor de cunho linguístico e histórico. O primeiro pelo enriquecimento do vocabulário do falante, ao deparar com palavras novas; ou mesmo no 
contato com palavras de seu domínio linguístico, mas em casos de polissemia ou de sentido metafórico. O valor histórico se configura tanto no renascimento de palavras abandonadas pelo uso, como pela vivência de fatos históricos nos quais o uso das expressões representa uma visão de mundo.

Logo, com o intuito de promover a combinação dos temas caros ao ensino - língua, cultura e identidade propõe-se a análise do perfil de personagem do texto literário a partir do léxico, cuja análise oferece subsídios para que se perceba o conhecimento do sertanejo e a forma como apreende/representa a realidade. O estudo cuidadoso do léxico permite que se identifique a visão de mundo recorrente a determinado período histórico, em determinada região. Propõe-se, nessa vertente, a análise do romance Vidas Secas de Graciliano Ramos, com o objetivo de traçar o perfil do protagonista Fabiano, a partir do aparato lexical do romance.

Em função do potencial sígnico da obra, a teoria semiótica, aqui representada pela Teoria da Iconicidade Verbal (TIV), apresenta-se adequada à análise, desenvolvida por Simões em 2009, ampliada e aperfeiçoada em 2019. Essa teoria traz luz ao processo de significação da obra 
de Graciliano Ramos. Esse potencial perpassa todas as áreas da composição literária: da palavra ao texto, do enredo à estrutura narrativa, da personagem ao projeto comunicativo; nada escapa à perícia do romancista.

Segundo Simões, a iconicidade pode ser: lexical, isotópica e diagramática (SIMÕES, 2019, p. 94). O nível lexical, abordado nesta análise, apresenta o "potencial de ativação de imagens mentais" (SIMÕES, 2019, p. 99) durante a leitura, proporcionada pela carga icônica da palavra. É nessa vertente que as análises são apresentadas a seguir, a partir do potencial de significação do léxico constante da narrativa.

\section{FABIANO - APENAS MAIS UM SERTANEJO}

O romance Vidas Secas, publicado em 1938, retrata a vida de uma família de sertanejos, cujo objetivo principal é sobreviver à seca que assola o Nordeste do Brasil. Fabiano, o protagonista, representa um vaqueiro que não consegue se comunicar, devido à dificuldade que tem com as palavras. Em função disso, não consegue se expressar com clareza, muito menos defender-se das injustiças que sofre. A impossibilidade da personagem é representada iconicamente na narrativa construída em terceira pessoa, basicamente, em discurso indireto e indireto-livre. Essa estrutura não oferece a Fabiano a oportunidade de 
expressão; logo, seu perfil é construído a partir de um olhar externo, do narrador-observador. Nas poucas cenas em que Ihe é oferecido o poder da fala, sua inabilidade linguística Ihe impõe o silêncio.

Fabiano, desarraigado da própria terra, tangido pela seca, representa uma personagem sem origem conhecida cuja árvore genealógica é omitida - uma única vez, relembra sua infância com seu pai -, o sertanejo não é um fidalgo, mas um filho da terra. É dessa configuração que vem sua identidade, da terra. Felipe (2017) apresenta o processo de significação do substantivo Fabiano: um nome que remete à natureza, à fartura, índice de um homem "dotado de sorte e prosperidade". Segundo a autora,

a definição desse substantivo não encontra representatividade na caracterização da personagem de Graciliano Ramos, o que aponta para uma contradição na escolha do nome do sertanejo. Em outras palavras, a vida de Fabiano só pode ser associada a uma metáfora com a palavra "fava": o pouco ou quase nada que possuía eram "favas contadas": a mulher, os filhos e Baleia. (FELIPE, 2017, p. 30)

Sem direito a sobrenome, carrega apenas o prenome Fabiano. Substantivo, ícone de dupla significação, que contrasta à realidade apresentada na narrativa. Sua identidade construída no tecido textual apresenta um 
homem limitado pela força da natureza, representada pela seca, pela linguagem reduzida e pelas relações de poder narradas no romance.

O simbolismo da personagem rendeu-lhe um verbete especial em uma entrada em um dicionário geral; com referência ao uso regional alagoano, o Novo Aurélio Século XXI registra Fabiano como "1. Indivíduo inofensivo; pobre-diabo. 2. Indivíduo qualquer, desconhecido, sem importância. V. João ninguém" (FELIPE, 2017, p. 30).

$\mathrm{O}$ vaqueiro personifica um sem-número de sertanejos que migram para outras regiões em busca de meios de sobrevivência. Como a própria personagem assevera no fim do romance ao afirmar que "Chegariam a uma terra desconhecida e civilizada, ficariam presos nela. E o sertão continuaria a mandar gente para lá" (RAMOS, 1970, p. 172). A narrativa aponta para inúmeros retirantes que, num processo migratório, enfrentam situações que os levam a questionamentos quanto à sua identidade.

Os diversos paradigmas, a partir dos quais as identidades podem ser construídas ou fragmentadas, são frequentes no meio sociocultural. Woodward afirma que:

As formas pelas quais a cultura estabelece fronteiras e distingue a diferença são cruciais para compreenderasidentidades. Adiferença 
é aquilo que separa uma identidade da outra, estabelecendo distinções frequentemente na forma de oposições. [...] A marcação da diferença é, assim, o componente-chave em qualquer sistema de classificação. (WOODWARD, 2017, p. 42)

Além dos fatores políticos, "outros conflitos surgem das tensões entre as expectativas e as normas sociais" (WOODWARD, 2017, p. 33). Para Fabiano, essas expectativas e normas sociais eram bem claras. O seu lugar na sociedade estava marcado por um determinismo. Nascera para obedecer. Quando lidava com outras pessoas, tentava adequar-se ao meio como, por exemplo, às normas do "bem falar". Em função disso, atrapalhava-se ao tentar imitar a fala polida de seu Tomás da bolandeira; personagem que representa a pessoa letrada, que goza de valorização no seio da sociedade em função do conhecimento demonstrado.

O sistema de classificação citado por Woodward remete ao momento, quando o soldado amarelo fala "aqui tem gente" (RAMOS, 1970, p. 63), estabelecendo uma distinção entre ele e Fabiano, assim como em relação aos demais indivíduos presentes no momento, deixa clara a posição a partir da qual está falando. Seu posto de soldado, supostamente superior aos outros, demarca essa diferença, destituindo os outros de sua própria humanidade. 
O desencadeamento da crise de identidade de Fabiano dá-se a partir de dois fatos fundamentais. Primeiramente, de sua condição de itinerante, forasteiro em seu próprio país, em função das condições impostas pela seca estava sempre sujeito a um não-lugar. O sertanejo não experimentava o sentimento de pertencimento, tão necessário à estabilização da identidade. Woodward constata que

ao analisar como as identidades são construídas, sugeri que elas são formadas relativamente a outras identidades, relativamente ao 'forasteiro' ou ao 'outro', isto é, relativamente ao que não é. Essa construção aparece, mais comumente, sob a forma de oposições binárias [...]. Essa concepção de diferença é fundamental para se compreender o processo de construção cultural das identidades, [...]. A diferença pode ser construída negativamente - por meio da exclusão ou da marginalização daquelas pessoas que são definidas como 'outros' ou forasteiros. (WOODWARD, 2017, p. 50)

Fabiano estava sempre chegando ou saindo de um novo lugar. Quando acontecia de, metaforicamente, "criar raízes", logo chegava a seca e o tangia para longe. Em certo ponto da narrativa, satisfeito com a chegada das chuvas, o narrador relata que o vaqueiro "Aparecera como um bicho, entocara-se como um bicho, mas criara raízes, 
estava plantado" (RAMOS, 1970, p. 54). Essa condição era temporária, enquanto as aves de arribação não chegavam e a seca não os expulsava dali. A ideia de estar plantado denota uma adaptação ao lugar. Contudo, Fabiano estava sempre sujeito à transitoriedade no espaço, à desterritorialização, fatos inerentes à sua condição de migrante e determinantes no desenvolvimento da crise da identidade.

A segunda causa decorre da combinação: ser "um bicho" e ser homem. Espaço estreito no qual o vaqueiro figurava, visto que não se enxergava completamente homem, nem totalmente bicho. Para Fabiano, parecer-se com um animal era motivo de orgulho; "Sim senhor, um bicho, capaz de vencer dificuldades" (RAMOS, 1970, p. 54). Contudo, em vários momentos da narrativa Fabiano tenta convencer-se de sua humanidade. Não se vê exatamente como um bicho, mas também não se vê como ser humano por não ser como seus iguais e não ser tratado como tal.

Mas um dia sairia da toca, andaria com a cabeça levantada, seria homem.

- Um homem, Fabiano.

Coçou o queixo cabeludo, parou, reacendeu o cigarro. Não, provavelmente não seria homem: seria aquilo mesmo a vida inteira, cabra, governado pelos brancos, quase uma res na fazenda alheia. (RAMOS, 1970, p. 60) 
Retomando Woodward, o processo binário instala uma contradição na mente da personagem: ser bicho $X$ ser homem. A identidade é construída a partir não apenas das semelhanças, mas também das diferenças. É nesse processo que Fabiano experimenta um não-pertencimento, pois não se identifica completamente com nenhuma das duas possibilidades que a vida lhe apresenta: bicho ou homem.

O determinismo da obra é representado a partir da postura assumida pelo protagonista de Vidas Secas. Fabiano acreditava que aquele era seu destino e de outros sertanejos. Sua obediência às autoridades calcava-se na sua predestinação a ser um "cabra” mandado. Quando Fabiano fala "Você é um bicho, Fabiano" (RAMOS, 1970, p. 53), a visão de mundo impregnada nessa fala é aquela imposta pela sociedade da qual era apenas um coadjuvante.

No romance, o substantivo bicho é citado 18 vezes (FELIPE, 2017, p. 41). Desse total, dez estão relacionadas a Fabiano e sua família. Nesse mesmo trabalho, Felipe observa que "das 10 ocorrências em que a palavra bicho é direcionada à caracterização das personagens, em apenas duas [...] 0 vocábulo não apresenta carga negativa. Nas demais, o tom é pejorativo. Fabiano era um bicho: 'não tinha onde cair morto', 'vivia longe dos homens', 'entocado' (2017, p. 41). 
A insistência na repetição de uma palavra com tom depreciativo traz lume às intenções do narrador. Segundo Bakhtin, por mais que as palavras ou as frases repetidas sejam idênticas, como enunciado, elas jamais serão iguais. Afirma ainda que

enquanto enunciado (ou fragmento de enunciado), nenhuma oração, ainda que constituída de uma única palavra, jamais pode ser repetida, reiterada, duplicada: sempre teremos um novo enunciado (mesmo que em forma de citação). (BAKHTIN, 1997, p. 313)

O que está implícito na repetição é parte da estratégia de caracterização zoomorfizada do homem sertanejo, distanciando-o de sua essência humana. O processo de despersonalização atinge diretamente a identidade da personagem quando esta assume para si o que lhe é imposto repetidamente. Veja-se a fala de um estudioso da obra de Graciliano Ramos, em relação à cena em que o protagonista é castigado injustamente pelo fazendeiro que o empregava. Cristóvão assevera que

Fabiano verifica que o proprietário o repreende injustamente, pois todo o serviço decorria segundo as normas estabelecidas, mas comenta a anomalia invocando uma espécie de lei social: é da natureza deste tipo de relações humanas o domínio do mais forte traduzir-se pelo desrespeito do mais fraco. (CRISTÓVÃO, 1986, p. 203, grifo nosso) 
O processo de coisificação ao qual a personagem é submetida sugere um comportamento social repressivo personificado, no romance, por personagens que representavam autoridade sobre Fabiano: o patrão, o fiscal da prefeitura e o soldado amarelo. Segundo Felipe (2017) o processo de desumanização de Fabiano é concomitante ao processo de humanização de Baleia, a cadela de estimação da família de retirantes. Em análise detalhada, a autora demonstra como homem e animal são equiparados em suas ações e, até mesmo, em seus pensamentos. O raciocínio de Baleia, impossível a um animal racional, torna-se possível com o recurso do discurso indireto-livre desenvolvido pelo autor. $\mathrm{O}$ animal pensa, julga e raciocina tanto quanto seu dono.

A essência humana, representada pelo poder de raciocínio e de comunicação, é negada à família de retirantes. A realidade apresentada por Graciliano Ramos não se limita à paisagem nordestina, vai além do visível. Bakhtin analisa o processo de coisificação com a seguinte afirmação:

O realismo coisifica frequentemente 0 homem, mas isso não é uma aproximação com este. [...] O enfoque 'indutivo', que aparentemente é próprio do realismo, é, no fundo, uma explicação causal coisificante no homem. Aí, as vozes (no sentido de estilos sociais coisificados) se transformam 
simplesmente em indícios das coisas (ou sintomas de processos), a elas já não se pode responder, com elas já não se pode discutir, extinguem-se as relações dialógicas com tais vozes. (BAKHTIN, 1997, p. 317-318)

São muitas as vozes que, sem diálogo, ecoam na narrativa de Vidas Secas e reverberam, de geração em geração, determinando a saga dos sertanejos. As relações entre o mundo macro, da sociedade e dos governos, com o mundo micro do indivíduo provocam embates que, invariavelmente, desencadeiam uma crise na identidade do cidadão. A cisão entre esses dois mundos, concretizada no romance pela impossibilidade de diálogo entre o vaqueiro e a sociedade como um todo, é inicialmente representada pela ausência de desenvoltura linguística do protagonista, reforçado pelo processo de coisificação, citado por Bakhtin.

O romance Vidas Secas destaca-se na abordagem do ser humano em sua essência. Logo, a despeito da localização de qualquer obra literária em um tempo e um espaço determinados ou de sua classificação em um estilo literário, o potencial sígnico de sua composição ultrapassa qualquer enquadramento ou limite cronológico. A relação nãodialógica apresentada no romance ultrapassa a fronteira do gênero textual e alcança o ser humano naquilo que o identifica. Calcada nessa possibilidade de abordagem, 
buscou-se compreender o processo de cisão, ou de desencadeamento, da crise da identidade do protagonista.

\section{AS RELAÇÕES DE PODER NA COSMOVISÃO DE FABIANO}

A identidade de Fabiano é construída a partir de dois paradigmas. O primeiro, calcado no sentimento de pertencimento à terra, sentimento que passava de geração em geração, "Tinha vindo ao mundo para amansar brabo, curar feridas com rezas, consertar cercas de inverno a verão. Era sina. O pai vivera assim, o avô também" (RAMOS, 1970, p. 139). O cuidado com a terra e com o gado era tudo o que o vaqueiro sabia fazer. $O$ segundo paradigma diz respeito à autoridade estabelecida. Fabiano entendia a estruturação da sociedade em classes sociais, na qual os que tinham melhor condição financeira, ou maior conhecimento, eram superiores aos desafortunados como ele.

O primeiro paradigma é quebrado pela própria condição de itinerante dos sertanejos. Em tempos de seca, a escassez de recursos e de água impõe a migração como condição necessária à sobrevivência. O processo de desterritorialização é uma das causas da crise de identidade de Fabiano, um homem da terra, que tem seu sentimento de pertencimento destruído por causa da seca. Para o protagonista "Quem é do chão não se trepa. Pouco a pouco 
o ferro do proprietário queimava os bichos de Fabiano. E quando não tinha mais nada para vender, o sertanejo endividava-se (RAMOS, 1970, p. 135).

Sem condições de viver da terra nem do gado, Fabiano se sujeita a viver de fazenda em fazenda, trabalhando em troca do suficiente para sobreviver à seca. Por outro lado, o respeito ao governo e às autoridades estabelecidas, reconhecidas pelo sertanejo, também estão em colapso, uma vez que tais paradigmas entram em franco processo de contradição.

Isso fica claro no respeito que devotava a seu Tomás da bolandeira por causa de seu conhecimento, na obediência ao fiscal da prefeitura e na submissão aos desmandos do soldado amarelo e do patrão. A desconstrução dessa identidade inicia quando Fabiano percebe as contradições de tudo aquilo em que acreditava. Primeiramente, acreditava na importância de seu Tomás da bolandeira, homem letrado, de quem o vaqueiro tentava copiar umas palavras em "momentos de precisão". "Isto é. Vamos e não vamos. Quer dizer. Enfim, contanto etc. É conforme" (RAMOS, 1970, p. 63). As palavras difíceis de seu Tomás da bolandeira de nada Ihe adiantam com a chegada da seca. "Pois viera a seca, o pobre do velho, tão bom e tão lido, perdera tudo, andava por aí, mole. Talvez 
já tivesse dado o couro às varas, que pessoa como ele não podia aguentar verão puxado" (RAMOS, 1970, p. 57).

Por outro lado, ao ver-se pressionado pelo fiscal da prefeitura a pagar imposto por causa da carne de porco que fora vender na cidade, Fabiano tenta protestar, mas, não havendo argumentos para fugir da lei, restava-lhe obedecer. "Nem lhe restava o direito de protestar. Baixava a crista. Se não baixasse, desocuparia a terra, largar-se-ia com a mulher, os filhos pequenos e os cacarecos. Para onde? Hem? Tinha para onde levar a mulher e os meninos? Tinha nada!" (RAMOS, 1970, p. 138-139).

O fiscal da prefeitura e o soldado amarelo representam autoridades oficiais, o governo que, em sua concepção, tem obrigação de proteger as pessoas. Contudo, não é essa a experiência que Fabiano tem no contato com os representantes da lei. A figura contraditória do soldado amarelo é um símbolo das contradições de um governo que apregoa uma coisa, mas age de forma oposta.

O próprio nome que identifica o representante da autoridade, soldado amarelo, carrega em si uma ambiguidade. Segundo Felipe,

- soldado amarelo, também portador de dupla iconicidade, tem os ícones de autoridade, força e coerção [provenientes 
do significado do substantivo soldado] associados aos índices de fraqueza e covardia [provenientes do adjetivo amarelo]. Ressalta-se ainda que a função exercida por essa personagem está acima do indivíduo. O soldado amarelo não tem nome, é o agente / símbolo de um Governo ambíguo e contraditório. (FELIPE, 2017, p. 91, grifos do autor)

A despeito das limitações impostas a Fabiano, seu poder de raciocínio não é afetado. O sertanejo tem consciência de que o fiscal da prefeitura e o soldado amarelo são apenas peças de uma engrenagem chamada governo. Em suas conjecturas, Fabiano assevera "Os soldados amarelos são uns desgraçados que precisam morrer. Mata o soldado amarelo e os que mandam nele" (RAMOS, 1970 p. 157). Na construção da narrativa, o discurso indireto-livre mistura o pensamento do protagonista ao do narrador. Convencido da autoridade inerente ao representante do governo, o sertanejo relativiza a surra que levara "Enfim apanhar do governo não é desfeita, e Fabiano até sentiria orgulho ao recordar-se da aventura" (RAMOS, 1970, p. 149).

No relacionamento com as forças destrutivas e esmagadoras do mundo externo, a vida marginalizada é configurada pela cosmovisão da personagem de Fabiano, completamente ignorado, fora do mundo. Um mundo 
reconhecido por ele próprio como distante, "Para lá dos montes afastados havia outro mundo, um mundo temeroso; mas para cá, na planície, tinha de cor plantas e animais, buracos e pedras" (RAMOS, 1970, p. 169).

Fabiano representa um sem-número de sertanejos que, ainda nos dias de hoje, saem de sua terra em busca de sobrevivência em grandes capitais. Tangidos pela seca ou pela falta de trabalho, essas personagens da vida real têm sua identidade marcada pela falta, pela desterritorialização e pelo distanciamento de suas raízes. Essa configuração do romance de Graciliano Ramos concede um traço de atualidade à sua obra, que não pode ser ignorada nas salas de aula do ensino básico.

\section{PALAVRAS FINAIS}

As análises aqui propostas, calcadas na Teoria da Iconicidade Verbal, denotam a necessária conexão que o pesquisador precisa ter com o mundo que o cerca, mediante a análise de fenômenos políticos e sociais que refletem diretamente nos fatos linguísticos. É a observação atenta dessa realidade que faz com que a curiosidade do cientista resulte em descobertas fundamentais para 0 desenvolvimento científico-acadêmico. É nesse contexto, que encontramos a produção de Darcilia Simões. 
A autora sempre esteve atenta à necessidade do desenvolvimento de estratégias que contemplassem o ensino da leitura e da produção de textos, defendendo tais práticas como instrumentos para o desenvolvimento da pessoa e para o exercício da cidadania. Essa preocupação está refletida no SELEPROT - Semiótica, Leitura e Produção de Textos - Grupo de pesquisa idealizado por ela e criado para o desenvolvimento de pesquisas voltadas para o ensino de Língua Portuguesa.

No presente texto, destacamos a obra literária - legítima representante da cultura de um povo - como córpus necessário às aulas de Língua Portuguesa. Seja como simples fruição, seja com o fito de uma análise criteriosa, o texto literário permite que o leitor/aluno desenvolva seu conhecimento enciclopédico, enriqueça seu vocabulário e identifique traços da identidade cultural de um povo. Além disso, a associação do texto literário com informações recebidas no âmbito de outras disciplinas como a História, a Filosofia e a Sociologia, permite que o contexto sóciohistórico seja resgatado na malha textual, a partir da qual, o leitor reforça o conteúdo apreendido.

Os resultados aqui apresentados, com o auxílio da Teoria da Iconicidade Verbal, corroboram a necessidade 
da abordagem linguístico-cultural no ensino de línguas, com vista a um ensino profícuo da Língua Portuguesa. Esse entendimento independe das dimensões do território ou do alcance da língua falada. Entretanto, torna-se ainda mais necessário quando o alcance da língua ocorre num país com as dimensões do Brasil, cuja diversidade exige dos profissionais da sala de aula uma visão ampla do seu objeto de estudo, para um ensino consistente e consciente.

\section{REFERÊNCIAS}

ANTUNES, Irandé. Língua, texto e ensino: outra escola possível. São Paulo: Parábola editoria, 2009.

BAKHTIN, Mikhail. Estética da criação verbal. São Paulo: Martins Fontes, 1997.

BRASIL. Ministério da Educação. Base Nacional Comum Curricular (BNCC). Brasília: MEC, 2019. Disponível em: http://basenacionalcomum.mec.gov. br/images/BNCC_20dez_site.pdf. Acesso em: 26 jun. 2019.

BRASIL. Ministério da Educação. LDB: Lei de diretrizes e bases da educação nacional. 2. ed. Brasília: Senado Federal, Coordenação de Edições Técnicas, 2018.

BRASIL. Ministério da Educação. Secretaria de Educação Fundamental. Parâmetros curriculares nacionais: terceiro e quarto ciclos do ensino fundamental: língua portuguesa. Brasilia: MEC/SEF, 1998. Disponível em: http:// portal.mec.gov.br/seb/arquivos/pdf/portugues.pdf. Acesso em: 22 jun. 2018.

CRISTÓVÃO, Fernando. Graciliano Ramos: estrutura e valores de um modo de narrar. 3. ed. Rio de Janeiro: José Olympio, 1986.

FELIPE, Márcia da Gama Silva. Os signos da contradição em Vidas Secas. 93 p. Dissertação (Mestrado em Língua Portuguesa) - Universidade do Estado do Rio de Janeiro, Rio de Janeiro, 2017. 
RAMOS, Graciliano. Vidas Secas. 27. ed. São Paulo: Livraria Martins, 1970. SIMÕES, Darcilia. Para uma teoria da iconicidade verbal. São Paulo: Pontes Editores, 2019.

SIMÕES, Darcilia. Língua Portuguesa e cidadania: uma perspectiva multidialetal para o ensino. In: SIMÕES, Darcilia; HENRIQUES, Claudio Cezar. Língua e Cidadania: novas perspectivas para o ensino. Rio de Janeiro: Editora Europa, 2004, p. 89-113.

WOODWARD, Kathryn. Identidade e diferença: uma introdução teórica e conceitual. In: SILVA, Tomaz Tadeu da (Org.). HALL, Stuart; WOODWARD, Kathryn. Identidade e diferença: a perspectiva dos estudos culturais. 15. ed. Petrópolis, RJ: Vozes, 2017, p. 133.

Márcia da Gama Silva Felipe é doutora em língua portuguesa (UERJ/2019), título defendido com a tese Identidade em crise: a década de 1930 e seus reflexos na obra de Graciliano Ramos; mestre em Língua Portuguesa (UERJ/2017), título defendido com a dissertação "Os signos da contradição em Vidas Secas", ambos sob a orientação da professora Darcilia Simões. Professora concursada de Língua Portuguesa e Literatura nas redes municipal e estadual do Rio de Janeiro. Professora de Redação Acadêmica na UERJ. Membro do grupo de pesquisa Semiótica, Leitura e Produção de textos (SELEPROT), da Asociación de Linguística y Filología de América Latina (ALFAL) e da Associação Internacional de Linguística do Português (AILP). Desenvolve pesquisa nas seguintes temáticas: semiótica, leitura e produção de texto, uso da literatura no ensino da Língua Portuguesa. 